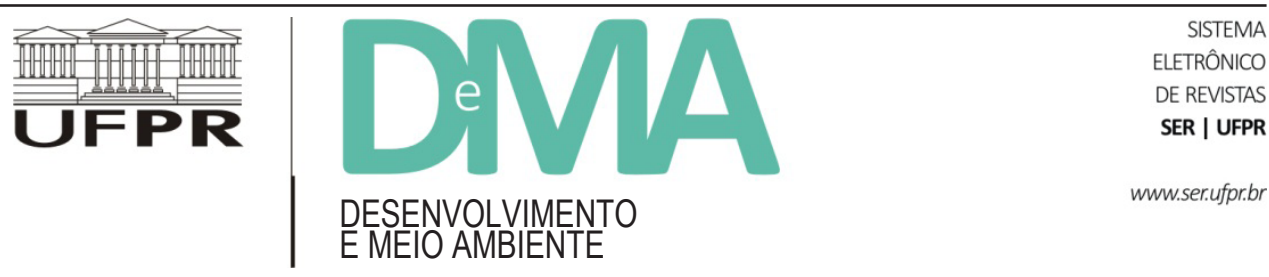

\title{
Depoimento de Francisco Mendonça $^{1}$
}

O MADE À MAGDA ZANONI: Fragmentos de reconhecimento e agradecimento!

Corria a década de 1990 e o Brasil, de maneira geral, registrava cada vez maior eco aos clamores internacionais para a redemocratização da sociedade e a conscientização e a defesa do meio ambiente. Advindo de movimentos ambientalistas gerais, iniciados sobretudo nos países desenvolvidos do Ocidente, tal clamor repercutiu posteriormente nos países não desenvolvidos. Esse relativo atraso acarretou, inclusive, estágios distintos da inserção das economias não desenvolvidas na agenda de debates e políticas priorizadas pelos países desenvolvidos ou pelas instituições mundiais de deliberações políticas.

A realização da Conferência do Rio, ou Eco92, constitui um marco culminante na história ambiental do século XX. Ela não somente colocou as preocupações ambientais dentre as mais relevantes questões, mas resultou também em derivações variadas na ordem institucional vigente. No Brasil, de maneira especial, os reflexos das deliberações do certame se fizeram observar numa multiplicidade de práticas econômicas, regulamentações legais, procedimentos, instituições, etc.

Dentre os vários reflexos decorrentes das discussões e deliberações da Rio-92, aquele que reorienta práticas de pesquisa e acadêmicas tomou importante destaque. A necessária passagem, ou transformação, de um contexto no qual predominava a perspectiva separatista da ciência para abordagens mais interativas e complexas se colocou como um desafio maior, uma exigência da abordagem ambiental daquele momento.

Um conjunto variado de iniciativas voltadas à abordagem ambiental e à defesa do meio ambiente ganhou, assim, evidência na fase final do século passado em pleno momento de maior explicitação da globalização como processo marcante daquele momento. No âmbito científico-acadêmico, tomaram vulto inúmeras iniciativas visando ao debate de ideias, especialmente com a organização de seminários, colóquios, congressos, etc. como passo

\footnotetext{
${ }^{1}$ Professor Titular do Departamento de Geografia e do Programa de Pós-graduação em Meio Ambiente e Desenvolvimento (PPGMADE) da UFPR. Atualmente (2018) é Pró-reitor de Pesquisa e Pós-graduação da UFPR.
} 
necessário para mudanças institucionais, redefinição de valores e de práticas de produção do conhecimento científico e técnico.

Nesse contexto de intensos debates e importantes transformações institucionais e culturais é que o MADE - Curso de Doutorado em Meio Ambiente e Desenvolvimento - da UFPR foi criado. Sua gênese resultou de um considerável esforço de intelectuais e cientistas que, cônscios de importantes demandas do contexto histórico, lançaram a ousada proposta de fundação de um curso de alto nível em meio ambiente e desenvolvimento calcado numa pedagogia interdisciplinar. Essa iniciativa, extremante ousada e inovadora, iria interferir, de maneira direta e indireta, na estrutura funcional e na dinâmica de uma instituição secularizada e marcada por procedimentos fortemente positivistas na promoção do conhecimento.

Foi naquele acalorado movimento e momento que tive a alegria e honra de encontrar uma incansável lutadora em defesa da justiça social, da democracia e do meio ambiente. Esta lutadora, Magda Zanoni, estava intrinsecamente envolvida com os debates, com as lides institucionais e se empenhava fervorosamente na construção da proposta do doutoramento em meio ambiente e desenvolvimento. A aprovação do curso, obviamente eivada de acalorados debates, ia muito além das clássicas formações de doutorado vigentes da UFPR, uma vez que se integrava diretamente aos processos de desenvolvimento da localidade de estudo definida para o inicio dos trabalhos (Mata Atlântica e Litoral do Estado do Paraná). Através de ações extensionistas, os professores e doutorandos da primeira turma se integravam a diferentes grupos sociais daquela área, buscando alternatividades econômicas para sua manutenção e também para a perenização da natureza - ecossistemas.
Os desafios eram de grande monta, mas a energia e o entusiasmo dos integrantes daquele grupo inicial não esmoreciam diante dos incontáveis obstáculos deparados ao longo do processo. A liderança e a sagacidade daquela "pequena notável", de fala intensa e voz retumbante, foram capazes de não somente assegurar o ambiente autocrítico e de qualidade cientifica necessário àquela empreitada, mas efetivamente de articular uma grande variedade de atores - nacionais e internacionais - de grande valia para o sucesso daquele processo.

Àquela primeira turma seguiram-se várias outras, ingressadas bianualmente no doutorado, mais tarde também no mestrado. A segunda turma ingressou no ano de 1995 e, sob o instigante questionamento lançado por Magda Zanoni, dedicou-se aos estudos e ao desvendamento da "Capital Ecológica", slogan que marcava uma nova fase do desenvolvimento urbano de Curitiba. Muito ocupada com a construção da interdisciplinaridade da primeira turma, ela não pôde se envolver diretamente com a segunda. Convidou então eminentes colegas afeitos ao trato dos temas urbanos, especialmente ao Prof Yanis Tsiomis (um renomado arquiteto vinculado à Université Paris La Villete) e outros urbanistas brasileiros mas, por diferentes motivos, a a turma acabou ficando sob nossa coordenação. A partir dos exemplos e da experiência que Magda Zanoni, juntamente com Claude Raynaut, Angela Duarte Damasceno Ferreira, Dimas Floriani, Maria do Rosário Knechtel, Paulo Lana, Rodolfo Angulo e Ademar Heemann, entre outros, desenvolviam na turma, pudemos elaborar o programa da turma II e implementá-lo. Foram anos de intenso trabalho e profundo aprendizado, que habilitaram os colegas do MADE a desenvolverem, com autonomia, a formação das turmas que se seguiram até o presente momento. 
Em nossos primeiros contatos com Magda ganharam destaque alguns questionamentos que se colocavam na ordem do dia em meados dos anos 1990 em outras instâncias, mas que se refletiam diretamente no contexto da UFPR. Dentre eles, ressalto aquele relativo à inserção das questões ambientais no âmbito das ciências sociais, o qual gerou calorosos debates nos primeiros anos de nosso trabalho conjunto. Para além do quadro disciplinar, deparávamo-nos então com os desafios que a questão ambiental suscitava... De maneira direta, nos questionávamos: como pode uma bióloga transitar tão bem, com tanta segurança e desenvoltura, no campo das ciências sociais? Como consegue ela integrar perspectivas naturalistas a perspectivas sociológicas e políticas no trato dos problemas ambientais? O que anima e dá tanta energia e capacidade de luta a essa mulher? Enfim, ela nos inspirava e nos desafiava na busca de respostas a infindáveis questões, já que ela própria se colocava muito mais numa posição de questionadora do que de reificadora de teorias e métodos já clássicos da produção do conhecimento. Era na perspectiva da multi e interdisciplinaridade, da multi e intersetorialidade, da junção entre a ciência clássica e a pós-modernidade, etc. que ela nos chamava ao debate e à construção de novas perspectivas de produção e reprodução do conhecimento.

Além de suas preocupações e envolvimento com construções cientifico-acadêmicas na fronteira do conhecimento, Magda Zanoni estava sempre fortemente envolvida com causas sociais das mais diferentes reivindicações relacionadas aos direitos humanos e à defesa da justiça social. Acompanhávamos, via noticias variadas, suas múltiplas e diferentes inserções em lutas na Europa, África, América Central e América do Sul, vivenciadas com tanta emoção e entrega que a faziam se deslocar rápida e surpreendentemente para as mais diferen- tes localidades do planeta. E o seu engajamento se produzia como que por mágica, tamanha era sua identificação com o sentido de liberdade e justiça dos povos... ela era, indubitavelmente, uma mulher muito além de seu tempo!

Mas nossa aproximação e trabalho conjunto se deu mesmo no âmbito acadêmico-cientifico; foi por e através do PPGAMDE - Programa de Pós-graduação em Meio Ambiente e Desenvolvimento (o qual se tornou um programa com a criação do curso de mestrado em 2008) que tive a honra e a oportunidade de atuar ao lado desta pessoa de caráter ilibado, rigor teórico-metodológico, honestidade ímpar, ousadia e postura critica avançada e de vanguarda. Foi por intermédio dela que a UFPR, via MADE, conquistou a Cátedra UNESCO para o Desenvolvimento Sustentável, atribuída em 1993 e que muito ilustra e dá brilho à formação oferecida pela instituição sede do curso. Em várias oportunidades nos reunimos com a administração da UNESCO em Paris visando tanto a implementação de novos programas e atividades quanto à manutenção da Cátedra, além do correto acompanhamento e chancelamento das atividades em curso. E, em todas as vezes, a presença da Profa Magda se constituía de uma caráter fundamental para o reconhecimento e sucesso do PPGMADE. Sua dedicação ao Programa era realmente algo sublime e admirável.

Muito ainda poderia acrescentar em relação à pessoa, à profissional e à militante Magda Zanoni. Sua trajetória e suas realizações deixaram marcas indeléveis em muitos de nós, amigos e colegas, em muitos estudantes e em muitas instituições e grupos de luta por onde passou. Era uma mulher com postura humilde diante da ciência, mas de extrema ousadia em face dos obstáculos positivistas e institucionais ao avanço do conhecimento.

No ano de 2004, a UFPR, por proposta do Colegiado do PPGMADE, outorgou à Profa Magda 
Zanoni o título de Doutor Honoris Causa. Aquela foi uma festa muito bonita e também uma forma acadêmica-oficial de reconhecer e agradecer o profundo apoio que ela dedicou à criação do curso e ao avanço da universidade. Naquela oportunidade, nos enchemos de júbilo e alegria em poder mostrar a ela parte de nossa gratidão... e quão contentes ficamos ao registrar a felicidade dela com nosso ato!

Magda nos deixou no ano de 2015 mas não se afastou de nós. Ela nos deixou lições de luta, ousadia e entusiasmo diante de adversidades gerais... nos ensinou que a luta e a democracia andam juntas, e que devem estar em nossa expectativa da construção de um mundo melhor!

Lembrar de Magda é motivo de satisfação... e, à sua lembrança, ocorre-me de lembrar também destas belas palavras da poeta Cora Coralina que, tanto quanto ela e no seu tempo, ousou e brilhou:

\section{OFERTAS DE ANINHA (AOS MOÇOS)}

Cora Coralina

Eu sou aquela mulher

a quem o tempo muito ensinou.

Ensinou a amar a vida.

Não desistir da luta.

Recomeçar na derrota.

Renunciar a palavras e pensamentos negativos.

Acreditar nos valores humanos.

Ser otimista.

Creio numa força imanente que vai ligando a família humana numa corrente luminosa de fraternidade universal.

Creio na solidariedade humana.

Creio na superação dos erros e angústias do presente.

Acredito nos moços.

Exalto sua confiança, generosidade e idealismos.

Creio nos milagres da ciência e na descoberta de uma profilaxia futura dos erros e violências do presente.

Aprendi que mais vale lutar do que recolher dinheiro fácil. Antes acreditar do que duvidar. 